\title{
Effect of Different Abutments and Connections in Deformation Crestal Bone
}

\author{
Mesquita, Alfredo Mikail Melo ; Silva, Juliano H M ; Saraceni, Cintia Helena Cury ; Kojima, Alberto N ; Özcan,
} Mutlu

\begin{abstract}
STATEMENT OF PROBLEM The use of Morse taper connections is increasing, but little is known about the biomechanical use of abutments and their use in fixed prostheses. PURPOSE This study evaluated the transmission of load on the bone implant-supported dentures, varying the type of prosthetic connection and abutment. MATERIAL AND METHODS Using 4 polyurethane models, 3 implants were inserted into each block, establishing the following groups: (a) external hexagon and Micro-Unit abutments; (b) external hexagon and UCLA abutment; (c) Morse taper and Micro-Unit abutments; and (d) Morse taper and UCLA abutments. The prosthetic structures were cast, and in a universal testing machine, load was applied midway between the implants, with cantilever intervals of 5, 10, 15, 20, and $25 \mathrm{~mm}$. Data were analyzed by Mann-Whitney, Friedman, and Kruskal-Wallis tests $(\mathrm{P}<0.05)$. RESULTS Regarding the prosthetic connection, there was no difference in the use of hexagonal or Morse taper, but the use of Micro-Unit abutment showed lower deformation values than UCLA for the 2 connections. CONCLUSIONS The use of intermediate abutments affects the distribution of masticatory loads: the greater the length of the cantilever, the greater the surface deformation of the bone around the distal implant.
\end{abstract}

DOI: https://doi.org/10.1097/ID.0000000000000419

Posted at the Zurich Open Repository and Archive, University of Zurich

ZORA URL: https://doi.org/10.5167/uzh-128189

Journal Article

Accepted Version

Originally published at:

Mesquita, Alfredo Mikail Melo; Silva, Juliano H M; Saraceni, Cintia Helena Cury; Kojima, Alberto N; Ȯzcan, Mutlu (2016). Effect of Different Abutments and Connections in Deformation Crestal Bone. Implant Dentistry, 25(3):328-334.

DOI: https://doi.org/10.1097/ID.0000000000000419 


\section{abutments}

AUTHORS: Alfredo Mikail Melo Mesquita, DDS, MSc, PhD*, Juliano H M Silva, DDS**, Cintia Helena Cury Saraceni, DDS, MSc, PhD***, Alberto N Kojima, \#, Mutlu Özcan, \#\#

\section{ABSTRACT: (292 WORDS)}

Statement of Problem: The use of Morse taper connections is increasing due to its biomechanical advantages and the natural formation of the switching platform, but little is known of the biomechanical influence use of abutments and use in fixed prostheses with cantilever.

Purpose: The aim of this study was to evaluate the transmission of masticatory load on the supporting bone implant-supported dentures depending on cantilever, varying the type of prosthetic connection (external hexagon and Morse taper) and abutment (Micro-Unit and UCLA).

Material and Methods: Using four polyurethane models (ASTM F-1839), three implants were inserted into each at a distance of $8 \mathrm{~mm}$, establishing the following groups: 1) external exagon and Micro-Unit abutments (HEMU); 2) external hexagon and UCLA abutment (HEU); 3) Morse taper and Micro-Unit abutments (CMMU); and 4) Morse taper and UCLA abutments (CMU). The prosthetic structures were fabricated using chemically activated resin cylinders based on $\mathrm{Co}-\mathrm{Cr}$, which were cast using a conventional brazing technique. Strain gauges were attached to the polyurethane between the implants and the distal implant closest to the cantilever. In a universal testing machine (2000RK - Kratos, São Paulo, Brazil), a load of $15 \mathrm{~kg}(150 \mathrm{~N})$ was applied midway between the placed implants, with cantilever intervals of $5,10,15,20$, and $25 \mathrm{~mm}$.

Results: The data were statistically analyzed for each strain gauge with Mann-Whitney Test $(\mathrm{p}<0,05)$, taking into account the length of the cantilever according to the Friedman and Kruskal-Wallis test $(\mathrm{p}<0,05)$.

Conclusions: The greater the length of the cantilever, the greater the surface deformation of the bone around the distal implant. Regarding the prosthetic connection, there was no difference in the use of hexagonal or Morse taper, but the use of Micro-Unit abutment showed lower deformation values than UCLA for the two connections. 
${ }^{*}$ Professor, Department of Prosthodontics, Paulista University (UNIP).

** Student of the Graduate Program, Master in Dental Clinics, Paulista University (UNIP).

${ }^{* * *}$ Head, Graduate Program in Dentistry (UNIP), Paulista University (UNIP).

\# Professor, Department of Dental Materials and Prosthodontics, Paulista State University (UNESP).

\#\# Professor, Dental Materials Unit, Center for Dental and Oral Medicine, Clinic for Fixed and Removable Prosthodontics and Dental Materials Science, University of Zurich

Reprint requests and correspondence to: Alfredo Mikail Melo Mesquita, DDs, MSc, PhD, Paulista University - Department of Prosthodontics - Rua Jorge Tibiriça 126 cep 041206-000 Vila Clementino, São Paulo (SP), Brazil

E-mail: alfmikail@yahoo.com.br 
If the load transfer of an implant, or from the implant to the surrounding bone, exceeds physiological limits, there may be resulting failures in rehabilitation or even loss of osseointegration. ${ }^{1}$

Among the biomechanical factors involved, the passivity of the metal structure of many prostheses reduces the preload on these implants, thus reducing the tensile forces that the structure may generate. ${ }^{2}$ The passive fitting of implant-retained prostheses is believed to allow the prosthesis to adapt with the smallest possible marginal misfit, passively adapting to the retaining component without creating stress in the implant itself or the surrounding bone. ${ }^{3}$

Thus, the prosthesis must be fitted with maximal passivity on the implants or intermediate abutments to achieve long-term success of the rehabilitation. ${ }^{4}$ Thus, any factors that reduce the preload force generated on the implant system/prosthesis must be considered and studied.

The type of abutment has a direct influence on the load distribution on the bone. One approach to minimizing distortions incorporated during the manufacture of prosthetic infrastructures is the use of intermediate abutments between the prosthetic infrastructure and the implant's prosthetic platform. In addition to fitting, the use of these abutments allows better distribution of the stress patterns generated by masticatory loads. ${ }^{5}$

The morphology and design of the prosthetic connection directly influence bone remodeling. ${ }^{6,7}$ Studies compared external and internal hexagon type prosthetic connections and noted that the internal design has a larger contact area that extends deeper into the implant, which leads to greater stability of the connection and better load distribution around the bone. ${ }^{5,8-10}$ The implant design biomechanically influences the distribution of loads only in cases of implants fitted immediately after extraction and does not affect cases of late loading. ${ }^{11}$ 
A high stress value can cause various undesirable consequences, such as the loss of the fastening screw, fracture of the set screw or of the implant itself, as well as other system structures, and possible biological complications such as mucositis, peri-implantitis, marginal bone loss, and loss of osseointegration. ${ }^{12}$

Therefore, load transfer at the bone-implant interface depends, among other factors, on the load type, the quantity and quality of supporting bone tissue, implant geometry, position, number and linear arrangement of the implants, size of the occlusal surface, excessive height of the abutment/crown, prosthesis interfaces, cantilever length, parafunctional occlusal habits, bite force, primary mechanical stability, and type of prosthetic retention. When the occlusal force exceeds the capacity of the osseointegrated interface to absorb stress, the implant is expected to fail. ${ }^{13}$

In a retrospective clinical analysis of the relationship between implant fracture and occlusal overload, found that $90 \%$ of fractures occurred in posterior segment implants supported by one or more implants in association with cantilever, bruxism, or high occlusal loads. ${ }^{14}$

In this in vitro study, the objective was to investigate, using extensometry, the distribution of masticatory loads on cantilever implant-supported prostheses and their effect on the surface around the implant, varying the prosthetic connection and type of prosthetic abutment.

\section{MATERIAL AND METHODS}

In this experiment, four models were employed that were produced from polyurethane with two densities, which simulated a 2-mm-thick cortical portion (density $40 \mathrm{pcf}$ ); the rest was a portion of spinal cord (density 20pcf), with overall dimensions of $22 \times 16 \times 150$ mm (CPR-02 model; Nacional Ossos), based on ASTM F-1839 requirements. 
For the insertion of parallel implants in the polyurethane blocks and the manufacture of casting patterns of the metal structures, an aluminum device was used that had metal rings threaded for the installation of implants similar to the Novum system.

The rings possessed diameters of $3.0,3.2$, and $3.6 \mathrm{~mm}$, which allowed drilling with surgical drills (Conexão Sistemas de Prótese) with diameters of 2.8, 3.0, and $3.4 \mathrm{~mm}$, respectively. An implant motor (Smart-Driller model; Driller) and a 20:1 reducing counter-angle (10400XLED; Anthogyr) with a speed of $1200 \mathrm{rpm}$ were used.

In two models, external hexagon self-screwing-implants were installed (Implant Grip; Conexão Sistemas de Prótese), and in the other two models, Morse taper implants were used (implant Torq; Conexão Sistemas de Prótese). All measured $3.75 \mathrm{~mm}$ in diameter and $11.5 \mathrm{~mm}$ in length. The implants in the samples were designated $\mathrm{A}, \mathrm{B}$, and $\mathrm{C}$ from left to right, with $\mathrm{C}$ being the implant closest to the cantilever (Figs. 1A and B).

Micro-Unit type components (Conexão Sistemas de Prótese) were installed in one of the models with external hexagon implants and one of the models with Morse taper implants. On the external hexagon implants, these components had a metal strap of $2 \mathrm{~mm}$ height and, on the Morse taper, a strap of height 2.5 $\mathrm{mm}$, the difference being due to the fact that the strap manufacturers do not currently provide straps of the same size. All Micro-Units were installed using a progressive torque wrench (Conexão Sistemas de Prótese) with up to $20 \mathrm{Ncm}$ torque, as recommended by the manufacturer.

At this point, the four groups were established as shown in Table 1 below:

The same device in aluminum used for the perforations provided the dimensions for the acrylic bar that would become part of the metal infrastructure, namely, $53 \times 4 \times 8 \mathrm{~mm}$. The locations were where the implants and the load application sites were installed; in these locations, there are low relief markings at intervals of $5,10,15,20$, and $25 \mathrm{~mm}$ distal to the last prosthesis implant. 
The resin bars were encased in cylinders $6 \mathrm{~mm}$ above the castable cylinder component joint with the aid of a periodontal probe, to compensate for the different heights of the Micro-Units, and they were joined by increments of resin with the aid of a brush, forming the casting patterns. (Fig. 2A,B,C,D). For groups with UCLA type abutments, it is important to note that UCLA type non-anti-rotational Co-Cr-based castable cylinders were used, as they are a fixed prosthesis.

After casting structures in $\mathrm{CoCr}$ using the conventional brazing technique, the surface of each block was cleaned with isopropyl alcohol, and three uniaxial extensometers were bonded onto the upper surface of the experimental polyurethane block, tangential to the implant platform. A small amount of cyanoacrylate adhesive (Super Bonder; Loctite) was applied to the contact surface of the extensometers. After correct positioning, digital pressure was exerted using a polyester strip for a period of 3 minutes. The electrical cables of each extensometer were soldered to an electric terminal, which provided a shielded electric cable.

Each metal structure was repositioned on its respective polyurethane pad and screwed onto the prosthetic connections with torque according to the manufacturer's instructions.

The extensometers were connected to an electrical signal conditioning unit via shielded electrical cables. Each extensometer formed a connection called a $120 \Omega$ quarter Wheatstone bridge, which is an appropriate electrical circuit for detecting minimal resistance changes caused by strain. These variations occur on a millionth scale (microvolts) and were recorded and amplified by the signal conditioning unit, extensometer bridge kit, Transtec, MDC-10 model (FAPESP 2012 / 50560-0), which, in addition to feeding the Wheatstone bridges, amplified the signal generated and performed the conversion from analog to digital.

Electrical changes were transformed arithmetically to microstrain units using the data acquisition software, which was also responsible for registering the information. 
Each extensometer corresponded to a channel of the extensometer conditioning unit, in the following order:
a) Channel 1 - implant B mesial (Extensometer 1);
b) Channel 2 - between implants B and C (Extensometer 2);
c) Channel 3 - implant $\mathrm{C}$ distal (Extensometer 3).

The models were then taken to a universal testing machine (2000RK - Kratos) for the application of a 150 $\mathrm{N}$ load on the metal bar at a point equidistant between the implants and on the cantilever at intervals of 5, 10, 15, 20, $25 \mathrm{~mm}$. Three measurements were made for each position. (Fig. 3)

The strain magnitude measured by each extensometer was recorded in microstrain $(\mathrm{m} \varepsilon)$. Before each reading, the apparatus was balanced and calibrated to $\pm 10 \mathrm{~m} \varepsilon$, with no stress in the experimental model. The data obtained from a total of 756 measurements ( 4 models, 3 extensometers, 7 application sites, 3 measurements) were statistically analyzed using the computer program BioEstat 5.3.

\section{RESULTS}

To better understand the results, an analysis was performed for each extensometer, initially analyzing the prosthetic connection factors and component type. The cantilever length factor was then analyzed.

For extensometer 1 (SG1), as observed in Table 2, there was no statistically significant difference in terms of prosthetic connection; however, there was a difference in abutment type, with the Micro-Unit type abutment having significantly lower values.

With respect to the cantilever length factor for extensometer 1, Table 3 shows that the longer the cantilever length, the greater the strain experienced on the bone surface. For loading on the cantilever, the Micro-Unit type component had lower bone surface tension values than the UCLA type component. 
In the surface strain analysis with respect to the second extensometer (SG2), there was a statistically significant difference between prosthetic connection types (Table 4), with lower strain values for the Morse taper connection type. There was also a difference between types of prosthetic components, with lower strain values for the Micro-Unit component.

With respect to the cantilever length factor for extensometer 2, Table 5 shows that the longer the cantilever length, the greater the strain experienced on the bone surface. For cantilever loading, the MicroUnit type component had lower bone surface stress values than the UCLA type component.

For extensometer 3 (SG3), as observed in Table 6, for the Morse taper type prosthetic connection, there was a significant difference when using the Micro-Unit abutment, but the difference did not exist for the External Hexagon. It can also be observed that the UCLA abutment had higher stress values when used with a Morse taper connection than with an External Hexagon connection.

With respect to cantilever length factor for extensometer 3, Table 7 shows that the greater the cantilever length, the greater the strain on the bone surface. In general, lower strain values could be observed when using Micro-Unit type components when the load is applied to the cantilever, and the use of the UCLA component generally showed higher strain values on Morse taper than on the other type.

As observed in Table 8, a comparative analysis between the extensometers used reveals that higher values were found on the distal side of the implant nearest to the cantilever.

\section{DISCUSSION}

The choice to study cantilever prostheses was made because this is a type of prosthetic rehabilitation that is much used clinically, in turn because there are many patients with systemic and anatomical conditions that preclude implant placement without conducting grafting procedures, especially in the rear segments of the maxilla and mandible. ${ }^{15,16}$ 
Implant-supported fixed prostheses with cantilevers have biological complications, as this type of prosthesis increases the load on the implant closest to the cantilever, which may lead to marginal bone loss by generating loads transmitted to the bone that are beyond its physiological threshold. ${ }^{17}$ It may also lead to mechanical issues, such as the loosening or fracture of prosthetic screws in excessive number. ${ }^{18}$

Some studies in the literature use human or bovine bone as an experimental model ${ }^{19,20}$, but bone is not a homogeneous substrate, and its physical properties vary according to species, age, gender, and bone type as well as the shape and size of the specimen, which determines different mechanical properties in various locations within the same specimen, thus compromising the reproducibility of research due to anisotropic behavior. $^{21,22}$ Another difficulty reported in a study that sought to validate the use of human bone for conducting extensometry research is the need to maintain this bone in a hydrated state. They found that to maintain its physiological characteristics of elasticity, it was necessary to freeze the bone in $-20^{\circ} \mathrm{C}$ saline after removal. $^{20}$

Polyurethane is therefore employed because this substrate is used in various research work with extensometry to simulate human bone marrow ${ }^{10,22-29}$. Such authors state that polyurethane has a modulus of elasticity similar to human bone (Polyurethane: $3.6 \mathrm{GPa} /$ medullary bone: 4.0 to $4.5 \mathrm{GPa}$ ) and is a homogeneous and isotropic substrate.

Extensometry is a strain measurement technique that is applied in a wide range of scientific and technological activities, covering various areas of engineering and life sciences. This technique makes it possible to obtain real data on the force exerted on the implant and transferred to the supporting structures. $^{21,24,30}$ For some authors, it is the methodology of choice for biomechanical analysis of implant supported prostheses. ${ }^{21,31}$

Extensometry is based on the fact that all the metal put under strain by an external force undergoes changes to its electrical resistance. ${ }^{24,32}$ The electrical resistance of a metal is directly proportional to its 
length and inversely proportional to its cross-section. If the metal is stretched, the length increases and the cross section decreases, thus increasing electrical resistance. If the metal is subjected to compressive forces, the cross-section increases, reducing the length and electrical resistance. ${ }^{32}$

By applying a force to a particular material, strain on its structural arrangement occurs. Strain is expressed as " $\varepsilon "$ (epsilon) and can be measured as the ratio between the dimensions of the object under stress and its original dimensions, generating absolute values without unity. These values are extremely small, and thus, the compression or relative elongation is expressed in $\mu \varepsilon$ (microstrain), a suffix used in this study that corresponds to $10^{-6} \varepsilon$. One thousand units of microstrain $(1000 \mu \varepsilon)$ correspond to the stretching or compression of $0.1 \%$ of the structure in question. ${ }^{33,34}$

Nishioka et al. ${ }^{28}$ emphasizes that the CoCr alloy has been increasingly used in supported fixed dental prosthesis and supported implants for its high corrosion resistance, which ensures its biocompatibility. This property combined with its low cost led to the choice of use of this alloy.

Casting patterns were obtained on the polyurethane model based on the elimination of variables such as molding material, molding techniques, positioning of the analog to obtain the functional model, and gypsum expansion, which may prevent the passive fit of the prosthesis. ${ }^{10,23,24,28,35}$

In his study, Goll ${ }^{35}$ recommends a clinical protocol to be followed when making prosthetic implants. One of the recommendations for measures to avoid mismatch of the prosthetic implant is casting in a single block. ${ }^{28}$ Watanabe et al. ${ }^{25}$ did not find a significant difference when comparing fitting stress in castings made in Monobloc with castings that were sectioned and then welded. In 2004, Heckmann et al. ${ }^{26}$ found no difference in fit between waxed monobloc prostheses on an extensometry test model and prostheses produced by transfer and welding techniques, regardless of whether cemented or screwed.

Cleaning the block surface with isopropyl alcohol and bonding with cyanoacrylate followed the linear extensometer bonding methodology used diferents authors. ${ }^{19,22}$ 
Extensometer bonding was performed strategically to record microstrain on the polyurethane in the region adjacent to the implant in the cervical direction according some authors. ${ }^{19,20,23-27}$ But another authors ${ }^{31,32,36,37}$ have bonded extensometers onto the surface of prosthetic abutments, but bonding in this region is difficult for the following reasons: the circular shape of the abutments makes bonding difficult and can result in errors during reading; the degree of strain suffered by this region is very low, which may mask the load distribution generated on the implant retention substrate; and the region around the implants is the area of the greatest distribution of masticatory load. ${ }^{19,25-27}$

When the load is applied to the cantilever, the extensometer of the implant distal nearest to the cantilever shows greater deformation, and the greater the cantilever length, the greater the surface strain on the bone, corroborating the study by Tashkandi et al. ${ }^{19}$

We could see at times that when applying the load on the cantilever, the bar bent, which may have influenced the lower results found for some extensometers.

In this study, we observed no difference in stress distribution on the bone according to the type of prosthetic connection - external hexagon or Morse taper - which corroborates the study by Pessoa et al. ${ }^{11}$, who analyzed different types of prosthetic connection. The work of Yang et al. ${ }^{10}$ found significantly lower values when comparing internal and external hexagon; however, the author notes that he found high surface strain values that could be harmful to the bone, just as in the values found in this study.

As reported by CHUN et al. ${ }^{5}$, in this study, there was a difference between the use of Micro-Unit components and UCLA regardless of prosthetic connection, wherein the Micro-Unit type components had lower load distribution values on the peri-implant bone.

In our view, the limitations of the current study model should be considered when interpreting the results of this work. For example, it is an in vitro study based on a homogeneous model with known mechanical 
properties, rather than bone. It therefore provided adequate stress measures and meant that $100 \%$ of implants were in contact with the model material. In vivo, other variables such as bone density, implant stability and bone-implant contact would have to be considered.

\section{CONCLUSION}

Within the limitations of this study, we can conclude the following:

- The greater the length of the cantilever, the greater the surface strain on the bone around the most distal implant.

- Regarding prosthetic connection, there was no difference in the use of External Hexagon or Morse Taper in load transfer to the surrounding bone.

- The Micro-Unit type component had lower strain values than the UCLA type for the two connections.

\section{DISCLOSURE}

\section{APPROVAL}




\section{REFERENCES}

1 Kenney R, Richards MW. Photoelastic stress patterns produced by implant-retained overdentures. J Prosthet Dent 1998;80:559-64.

2 Smedberg JI, Nilner K, Rangert B, et al. On the influence of superstructure connection on implant preload: a methodological and clinical study. Clin Oral Implants Res. 1996;7:55-63.

3 Millington ND, Leung T. Inaccurate fit of implant superstructures. Part 1: Stresses generated on the superstructure relative to the size of fit discrepancy. Int J Prosthodont. 1995;8:511-6.

4 Jemt T, Book K. Prosthesis misfit and marginal bone loss in edentulous implant patients. Int J Oral Maxillofac Implants. 1996;11:620-5.

5 Chun HJ, Shin HS, Han CH, Lee SH. Influence of implant abutment type on stress analysis. Int J Oral Maxillofac Implants 2006;21:195-202.

6 Shin YK, Han $\mathrm{CH}$, Heo SJ, et al. Radiographic evaluation of marginal bone level around implants with different neck designs after 1 year. Int J Oral Maxillofac Implants. 2006;21:789-94.

7 Palmer RM, Palmer PJ, Smith BJ. A 5-year prospective study of Astra single tooth implants. Clin Oral Implants Res. 2000;11:179-82.

8 Merz BR, Hunenbart S, Belser UC. Mechanics of the implant-abutment connection: an 8-degree taper compared to a butt joint connection. Int J Oral Maxillofac Implants. 2000;15:519-26.

9 Maeda Y, Satoh T, Sogo M. In vitro differences of stress concentrations for internal and external hex implant-abutment connections: a short communication. J Oral Rehabil. 2006;33:75-8.

10 Yang TC, Maeda Y. The biomechanical effect of platform switching on external- and internalconnection implants. Int J Oral Maxillofac Implants. 2013;28:143-7.

11 Pessoa RS, Coelho PG, Muraru L, et al. Influence of implant design on the biomechanical environment of immediately placed implants: computed tomography-based nonlinear three-dimensional finite element analysis. Int Maxillofac Implants. 2011;26:1279-87.

12 Lindquist LW, Rockler B, Carlsson GE. Bone resorption around fixtures in edentulous patients treated with mandibular fixed tissue-integrated prostheses. J Prosthet Dent 1988;59:59-63. 
13 Eskitascioglu G, Usumez A, Sevimay M, et al. The influence of occlusal loading location on stresses transferred to implant-supported prostheses and supporting bone: A three-dimensional finite element study. J Prosthet Dent 2004;91:144-50.

14 Rangert B, Krogh PH, Langer B, Van Roekel N. Bending overload and implant fracture: a retrospective clinical analysis. Int J Oral Maxillofac Implants 1995;10:326-334.

15 Becker CM, Kaiser DA. Implant-retained cantilever fixed prosthesis: where and when. J Prosthet Dent 2000;84:432-5.

16 Wennström J, Zurdo J, Karlsson S, et al. Bone level change at implant-supported fixed partial dentures with and without cantilever extension after 5 years in function. J Clin Periodontol 2004;31:1077-83.

17 Skalak R. Biomechanical considerations in osseointegrated prostheses. J Prosthet Dent 1983;49:843848.

18 Mcglumphy EA, Mendel DA, Holloway JA. Implant screw mechanics. Dent Clin North Am 1998;42:71-89.

19 Tashkandi EA, Lang BR, Edge MJ. Analysis of strain at selected bone sites of a cantilevered implantsupported prosthesis. J Prosthet Dent 1996;76:158-164.

20 Morton D, Stanford CM, Aquilino SA. Evaluation of resilient abutment components on measured strain using dynamic loading conditions. J Prosthet Dent 1998;80:46-51.

21 Rubo JH, Souza EAC. Computational methods applies to bioengineering: solution of load problems in implant prosthesis. Rev Fac Odontol Bauru 2001;9:97-103.

22 Vasconcellos LG, Nishioka RS, Vasconcellos LM, Nishioka LN. Effect of axial loads on implantsupported partial fixed prostheses by strain gauge analysis. J Appl Oral Sci 2011;19:610-5.

23 Assif D, Marshak B, Horowitz A. Analysis of load transfer and stress distribution by an implantsupported fixed partial denture. J Prosthet Dent 1996;75:285-91.

24 Clelland NL, Carr AB, Gilat A. Comparison of strains transferred to a bone simulant between as-cast and post-soldered implant frameworks for a five-implant-supported fixed prosthesis. J Prosthodont 1996;5:193-200.

25 Watanabe F, Uno I, Hata Y, et al. Analysis of stress distribution in a screw-retained implant prostheses. Int J Oral Maxillofac Implants 2000;15:209-18. 
26 Heckmann SM, Karl M, Wichmann MG, et al. Cement fixation and screw retention: parameters of passive fit. An in vitro study of three-unit implant-supported fixed partial dentures. Clin Oral Implants Res. 2004;15:466-73.

27 Karl M, Rosch S, Graef F, et al. Static implant loading caused by as-cast metal and ceramic-veneered superstructures. J Prosthet Dent 2005;93:324-330.

28 Nishioka RS, de Vasconcellos LG, de Melo Nishioka GN. Comparative strain gauge analysis of external and internal hexagon, Morse taper, and influence of straight and offset implant configuration. Implant Dent 2011;20:24-32.

29 Cerqueira NM, Ozcan M, Gonçalves M, et al. A strain gauge analysis of microstrain induced by various splinting methods and acrylic resin types for implant impressions. Int J Oral Maxillofac Implants 2012;27:341-5.

30 Spiekermann H, Donath K, Jovanovic S, Richter EJ. Biomechanics. In: Color atlas of dental medicine implantology. New York: Thieme Medical Publishers 1995:81-90.

31 Glantz PO, Rangert B, Svensson A, et al. On clinical loading of osseointegrated implants: a methodological and clinical study. Clin Oral Implants Res 1993;4:99-105.

32 Kim WD, Jacobson Z, Nathanson D. In vitro stress analyses of dental implants supporting screwretained and cement-retained prostheses. Implant Dent 1999;8:141-51.

33 Frost HM. Wolff's Law and bone's structural adaptations to mechanical usage: an overview for clinicians. Angle Orthod 1994;64:175-88. Review.

34 Wiskott HW, Belser UC. Lack of integration of smooth titanium surfaces: a working hypothesis based on strains generated in the surrounding bone. Clin Oral Implants Res 1999;10:429-44.

35 Goll GE. Production of accurately fitting full-arch implant frameworks. Part I: clinical procedures. J Prosthet Dent 1991;66:377-384.

36 Isa ZM, Hobkirk JA. The effects of superstructure fit and loading on individual implant units. Part I: the effects of tightening the gold screws and placement of a superstructure with varying degrees of fit. Eur J Prosthodont Restor Dent 1995;3:247-53. 
37 Isa ZM, Hobkirk JA. The effects of superstructure fit and loading on individual implant units. Part 2: the effects of loading a superstructure with varying degrees of fit. Eur J Prosthodont Restor Dent 1996;4:11-4. 


\section{LEGENDS}

Fig. 1 A and B - A: External hexagon implants; B: Morse taper implants

Fig. 2 A, B, C, D - Casting patterns: G1 - HEMU; G2 - HEU; G3 - CMMU; G4 - CMU

Fig. 3 - Load application time

Table 1 - Group conformation

Table 2.- Mean (standard deviation) of different implants and abutments for SG1, irrespective of distance.

Table 3.- Mean (standard deviation) of SG1 at different distances for each type of implant and abutment.

Table 4.- Mean (Standard deviation) of different implants and abutments for SG2, irrespective of distance.

Table 5.- Mean (standard deviation) of SG2 at different distances for each type of implant and abutment.

Table 6.- Mean (standard deviation) of different implants and abutments for SG3, irrespective of distance.

Table 7.- Mean (standard deviation) of SG3 for different distances for each type of implant and abutment.

Table 8.- Mean (standard deviation) of extensometry at different distances (SG1, SG2, and SG3) for each type of implant and abutment. 


\section{(6) 2 웅}

\section{Figure $1 \mathrm{~A}$}

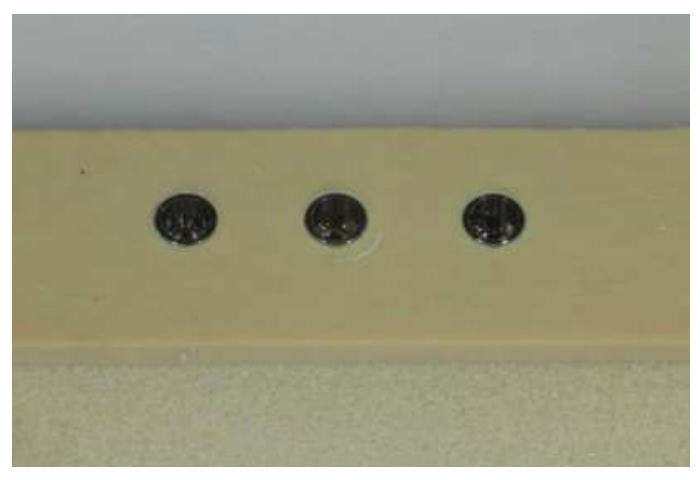

Figure 1B

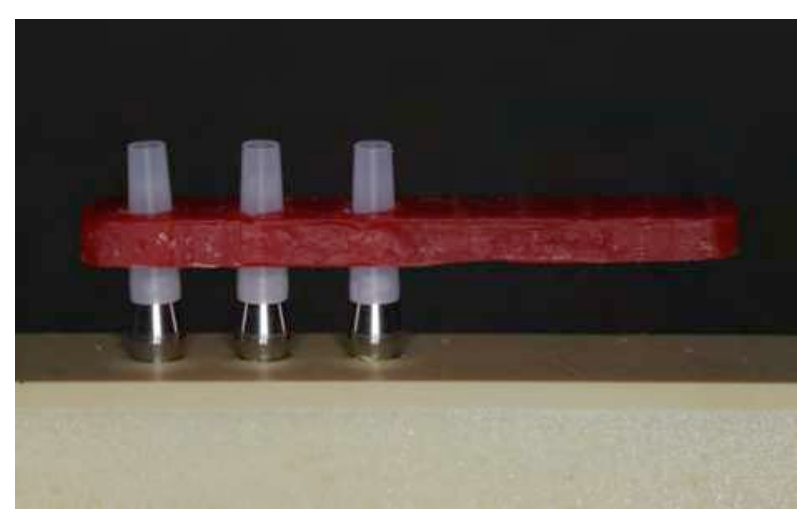

Figure 2A

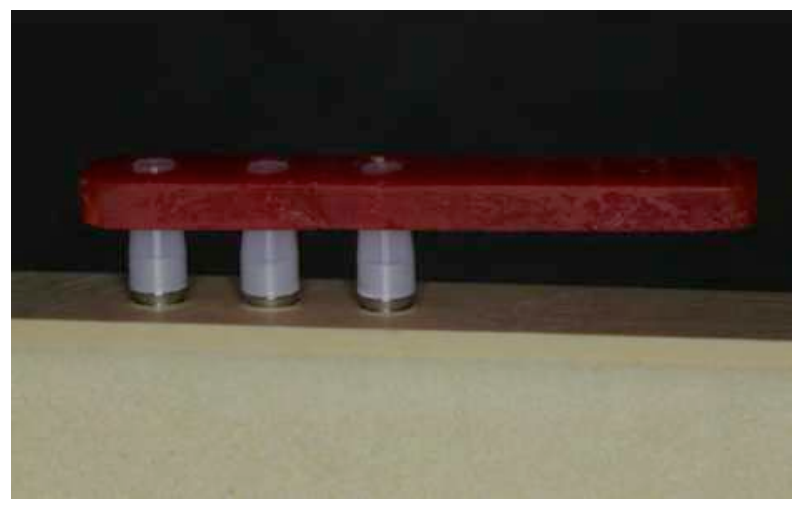

Figure 2B 


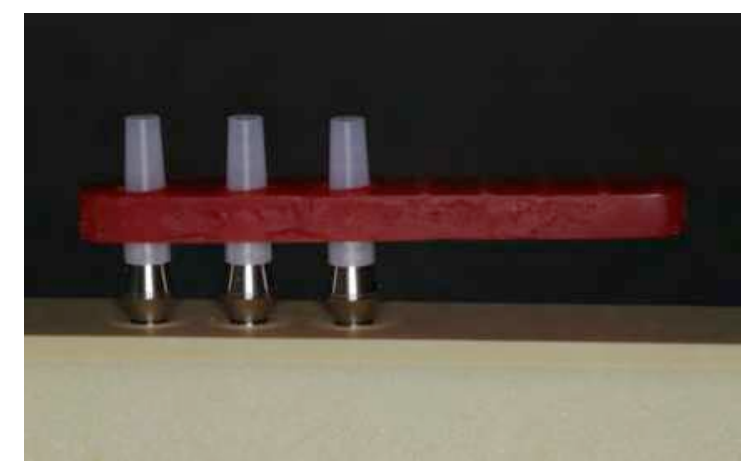

Figure 2C

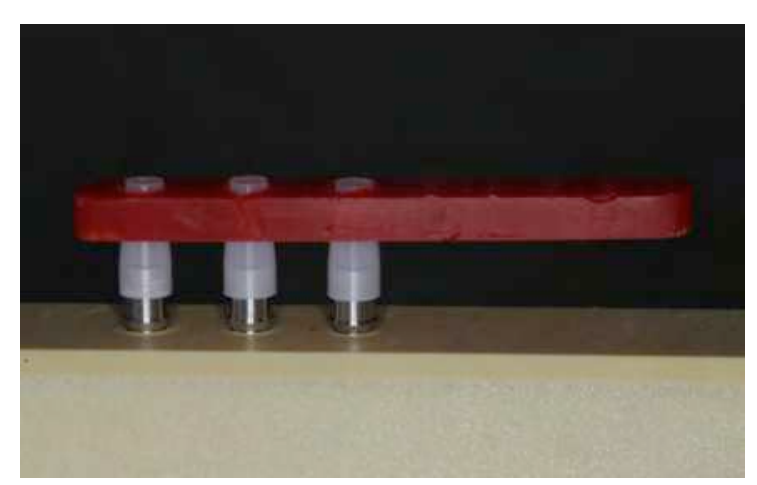

Figure 2D

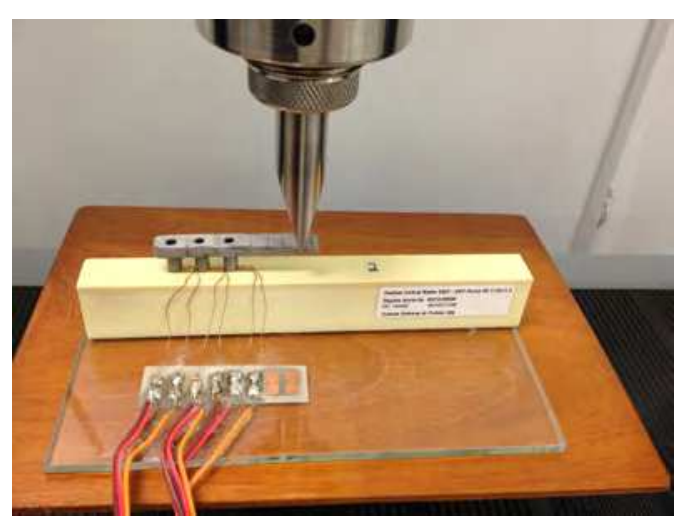

Figure 3 